\title{
(6) OPEN ACCESS \\ Minority stress factors as mediators of sexual orientation disparities in mental health treatment: a longitudinal population-based study
}

\author{
Richard Bränström ${ }^{1,2,3}$
}

\begin{abstract}
'Department of Clinical Neuroscience, Division of Psychology, Karolinska Institutet, Stockholm, Sweden ${ }^{2}$ Stress Research Institute, Stockholm University, Stockholm, Sweden ${ }^{3}$ Department of Chronic Disease Epidemiology, Social and Behavioral Sciences Division, Yale School of Public Health, Yale University, New Haven, USA
\end{abstract}

\section{Correspondence to} Dr Richard Bränström, Department of Clinical Neuroscience, Division of Psychology Karolinska Institutet, Nobels väg 9, Stockholm 171 77, Sweden; richard. branstrom@ki.se

Received 14 June 2016 Revised 17 November 2016 Accepted 25 November 2016 Published Online First 2 January 2017
CrossMark

To cite: Bränström R. J Epidemiol Community Health 2017;71:446-452.

\begin{abstract}
Background Substantial mental health disparities between lesbian, gay and bisexual (LGB) individuals compared with heterosexuals have been identified. The aim was to examine potential sexual orientation-based disparities in mental health treatment in a prospectively analysed population-based sample in Sweden and to explore potential moderators and mediators.
\end{abstract}

Method 30730 individuals from the Stockholm Public Health Cohort were followed up with questionnaires and registry-based health record data on psychiatric healthcare visits and prescription drug use between 1 January 2011 and 31 December 2011.

Results In adjusted analyses, gay and lesbian individuals were more likely to receive treatment for anxiety disorders (adjusted ORs (AOR) $=3.80 ; 95 \% \mathrm{Cl}$ 2.54 to 5.69 ) and to use antidepressant medication ( $\mathrm{AOR}=2.13 ; 95 \% \mathrm{Cl} 1.62$ to 2.79$)$; and bisexuals were more likely to receive treatment for mood disorders $(\mathrm{AOR}=1.58 ; 95 \% \mathrm{Cl} 1.00$ to 2.48 ), anxiety disorders ( $A O R=3.23 ; 95 \% \mathrm{Cl} 2.22$ to 4.72 ) and substance use disorders ( $A O R=1.91 ; 95 \% \mathrm{Cl} 1.12$ to 3.25$)$, and to use antidepressant medication (AOR=1.91; $95 \% \mathrm{Cl} 1.12$ to 3.25) when compared with heterosexuals. The largest mental health treatment disparities based on sexual orientation were found among bisexual women, gay men and younger lesbian women. More frequent experiences of victimisation/threat of violence and lack of social support could partially explain these disparities.

Conclusions This study shows a substantially elevated risk of poor mental health among LGB individuals as compared with heterosexuals. Findings support several factors outlined in the minority stress theory in explaining the mechanisms behind these disparities.

\section{INTRODUCTION}

An increasing body of research shows large mental health disparities between sexual minorities as compared with heterosexual individuals. ${ }^{1}{ }^{2}$ In particular, lesbian, gay and bisexual (LGB) youths have a greater risk for suicide attempts than non-LGB youths and higher prevalence of depression and anxiety diagnoses. ${ }^{3-5}$ Earlier studies have found that sexual minorities are between 1.4 and 4 times more likely to have a lifetime history of mental disorder when compared with heterosexuals. ${ }^{1-3} 6$

Sexual orientation health disparities have largely been explained through minority stress theory, which describes the excess stress that LGB individuals experience when compared with heterosexual individuals by virtue of their stigmatised sexual orientation. ${ }^{1}$ This minority stress, in the form of prejudice, discrimination, sexual orientation concealment, expectations of rejection and internalised stigma, additively combines with general life stress to confer adverse health outcomes. ${ }^{17}$ Studies have found higher exposure to stressors among sexual minorities than among heterosexuals regarding victimisation, ${ }^{8-10}$ employment discrimination, ${ }^{11} 12$ harassment at school $^{9}$ and family rejection. ${ }^{8}$ This increased exposure may partly account for sexual orientation disparities in mental health. ${ }^{13-15}$ In addition to the higher exposure to stressors, the minority stress model also describes stress-ameliorating factors such as social support, which can reduce the impact of minority stressors. ${ }^{1}$ Several recent studies have shown associations between low quality of social support and mental health problems among LGB individuals. ${ }^{16-20}$ Previous studies have also suggested that exposure to victimisation can interrelate with quality of social support to influence risk of poor mental health. ${ }^{21} 22$

From an intersectional perspective, sexual minority status is only one of many factors influencing people's health. The importance of exploring co-occurring sociodemographic characteristics that go together with elevated mental health problems within this population has been demonstrated in recent studies. ${ }^{23}{ }^{24} \mathrm{~A}$ better understanding is needed of the consequences of co-occurring characteristics with known associations to poor mental health, such as minority ethnicity status and low socioeconomic status. ${ }^{23}$ As an example from a Swedish context, it has been hypothesised that ethnic minority sexual minorities may be exposed to greater stress and health risks than native Swedes due to lower acceptance of homosexuality and greater discrimination in their country of origin and within their communities, but empirical evidence is lacking. The majority of earlier studies of the link between sexual orientation and mental disorders have included sociodemographic factors only as control variables or have not been large enough to directly compare the impact of various background factors on these outcomes. ${ }^{3} 2526$ However, recent studies suggest complex interactions between identities based on gender, age, sexuality, ethnicity and level of education with health outcomes. ${ }^{27-30}$

\section{AIMS OF THE STUDY}

The primary aim was to examine mental health treatment disparities between sexual minority individuals and heterosexuals in Sweden using a population sample followed longitudinally. A second aim was to examine if potential sexual orientation 
differences in mental health could be explained, or partially explained, by exposure to minority stressors (ie, victimisation, threat of violence) and ameliorating factors (ie, social support). Finally, we wanted to explore gender, age, country of birth, income, relationship status and level of education as possible effect modifiers of potential disparities.

\section{MATERIAL AND METHODS \\ Study sample}

The Stockholm Public Health Cohort is a prospective study managed by the Stockholm County Council. ${ }^{31}$ For this study, we used data for the 30730 individuals (18 years and older) recruited in the fall of 2010 that successfully returned a baseline paper-and-pencil mailed questionnaire or self-administered web survey (response rate: 61\%). In addition to a question regarding sexual orientation, the survey included questions regarding sociodemographic characteristics, health status and other life circumstances. Survey results were linked with data from national health and administrative registries using personal identification numbers. The study was approved by the Regional Ethics Committee in Stockholm, Karolinska Institute (number 2014/ $325-31 / 1)$.

\section{Self-report measures}

Sexual orientation-Individuals reported their sexual orientation by responding to an item phrased: 'What is your sexual orientation?' with the response categories: 'heterosexual', 'bisexual', 'gay/lesbian' and 'not sure'. A total of 28434 (92.5) individuals responded that they identified as heterosexual, $361(1.2 \%)$ as gay or lesbian, and $381(1.2 \%)$ as bisexual. We excluded 394 $(1.3 \%)$ individuals who responded that they were uncertain of their sexual orientation, as well as the 1160 (3.8\%) respondents who did not respond to the question. Those who did not respond were more likely to be older, female, single, have low income, be born outside of Sweden, and to have lower education than those who responded (all $\mathrm{p}<0.001)$. Those who responded that they were unsure of their sexual orientation were more likely to be single, have low income, be born outside of Sweden, and to have lower education than those who reported being gay/lesbian/bisexual or heterosexual (all $\mathrm{p}<0.001)$.

Household composition-One question was included regarding living situation and whether or not the respondent shared a household with a partner (yes/no).

Mental health determinants-Two questions were included regarding experiences of victimisation and threat of assaults during the past 12 months: 'During the past 12 months, have you ever been physically assaulted [yes/no]?' and 'During the past 12 months, have you ever been exposed to threats or threats of violence, severe enough to make you scared [yes/ no]?'. One question was used to assess social/emotional support: 'Do you have one or several individuals in your life, who can give you personal support in managing personal problems or crises in your life ['yes, always'; 'yes, most of the time'; 'no, usually not'; and 'no, never']?'.

\section{Registry-based data}

Social background factors-Information about gender, age, education, yearly disposable income and country of birth were collected from national registries and linked to the questionnaire data.

Mental health treatments-Mental health treatment was measured as the number of psychiatric healthcare visits and use of antidepressants. Count variables of inpatient care and outpatient specialist visits between 1 January 2011 and 31 December 2011, coded according to the International Statistical Classification of Diseases and Related Health Problems V.10 $(\mathrm{ICD}-10)^{32}$ diagnostic codes, were created. Mental health treatment was classified as the total number of visits during the specified 12 months period due to any mental diagnoses, that is, ICD-10: F00-F95. In addition, more specified analyses were conducted and healthcare visits were categorised into treatment for: mood disorders (ICD-10: F30-F39), anxiety disorders (ICD-10: F40-F48) or substance-related disorders (ICD-10: F10-F19). Data on use of antidepressant medication from the Prescribed Drug Register, according to the Anatomical Therapeutic Chemical (ATC) Classification System substance code: N06A (any use vs no use), were analysed.

\section{Statistical analysis}

In addition to examining descriptive statistics of the participants' responses by sociodemographics, we used regression models to examine sexual orientation differences in experiences of victimisation or threat of assaults, social support and mental health outcomes. Negative binomial regressions were used for count variables and logistic regressions for dichotomous outcomes. There were no missing data on our main outcome variables. Only respondents with complete data were analysed. The analyses of mental health outcomes were adjusted for a number of covariates: age, gender, income, education, relationship status and country of birth. In the first analyses of moderation by gender and age, stratified analyses were done if the interaction between sexual orientation and these variables was significant. A second set of analyses of more specific subgroup differences based on multiple sociodemographic factors was performed using a number of dummy variables. These variables were created through categorisation of participants based on all three variables: sexual orientation (ie, gay/lesbian, bisexual, heterosexual), gender (ie, male, female) and age (ie, 18-35 years, older than 35 years). The analyses were then performed with young heterosexual men as the reference category and all seven possible combinations of the included sociodemographic identity variables as predictor variables.

The analyses of mediation and moderation by victimisation/ threats and social support on mental health treatment were conducted in three steps. First, the mediating effects of victimisation/threats on the link between sexual orientation and mental health treatment were tested along with the potential moderating or buffering effect of social support on this mediation (through moderated mediation analysis). Second, the indirect effects of victimisation and social support as mediators of the link between sexual orientation and mental health treatment were tested (through multiple mediation analysis). Third, the moderating effects of all measured sociodemographic variables were tested. These analyses examined the potential moderating effect by sociodemographics on both the link between victimisation and mental health treatment, as well as the link between social support and mental health treatment. Analyses were performed using SPSS V.22 and mediation/moderation analyses were performed with the Hayes PROCESS macro for SPSS producing regression estimates with bias-corrected bootstrap CIs for the indirect effects. ${ }^{33}$

\section{RESULTS}

Table 1 presents sociodemographic characteristics, exposure to victimisation and threats, and social support by sexual 
Table 1 Sociodemographic characteristic and self-reported victimisation, threat of assaults, and social support by self-reported sexual orientation in the Stockholm Public Health Cohort 2010

\begin{tabular}{|c|c|c|c|c|}
\hline & $\begin{array}{l}\text { Gay/lesbian } \\
n=325\end{array}$ & $\begin{array}{l}\text { Bisexual } \\
n=392\end{array}$ & $\begin{array}{l}\text { Heterosexual } \\
n=12659\end{array}$ & \\
\hline Age & $\mathrm{M}(\mathrm{SD})$ & $\mathrm{M}(\mathrm{SD})$ & $\mathrm{M}(\mathrm{SD})$ & \\
\hline Years & $45.8(15.8)$ & $38.9(17.8)$ & $50.9(18.0)$ & $\mathrm{F}=96.67 * * *$ \\
\hline Education & $\mathrm{n}(\%)$ & $\mathrm{n}(\%)$ & $\mathrm{n}(\%)$ & \\
\hline Elementary school/high school & $173(53)$ & $7636(60)$ & $209(53)$ & $\chi^{2}=1.62$ \\
\hline University & $152(47)$ & $5023(40)$ & $183(47)$ & \\
\hline Individual income & $\mathrm{M}(\mathrm{SD})$ & $\mathrm{M}(\mathrm{SD})$ & $\mathrm{M}(\mathrm{SD})$ & \\
\hline Mean yearly income in (Swedish Kronor, in thousands) & $309(606)$ & $200(190)$ & $302(356)$ & $\mathrm{F}=15.33^{* * *}$ \\
\hline Relationship status & $\mathrm{n}(\%)$ & $\mathrm{n}(\%)$ & $\mathrm{n}(\%)$ & \\
\hline Living with partner/spouse & $196(54)$ & $195(51)$ & $18673(66)$ & $\chi^{2}=54.56^{* * *}$ \\
\hline Nation of birth & $\mathrm{n}(\%)$ & $\mathrm{n}(\%)$ & $\mathrm{n}(\%)$ & \\
\hline Sweden & $289(80)$ & $309(81)$ & $23655(83)$ & $\chi^{2}=11.95^{*}$ \\
\hline Other European country & $38(11)$ & $35(9)$ & $2946(10)$ & \\
\hline Non-European country & $34(9)$ & $37(10)$ & 1833 (6) & \\
\hline Victimisation, past 12 months & $\mathrm{n}(\%)$ & $\mathrm{n}(\%)$ & $\mathrm{n}(\%)$ & \\
\hline Yes & $13(4)$ & $21(6)$ & $629(2)$ & $\chi^{2}=21.24^{* * *}$ \\
\hline Threat of assault, past 12 months & $\mathrm{n}(\%)$ & $\mathrm{n}(\%)$ & $\mathrm{n}(\%)$ & \\
\hline Yes & $22(6)$ & $36(10)$ & $871(3)$ & $\chi^{2}=59.03^{* * *}$ \\
\hline Social support & $\mathrm{n}(\%)$ & $\mathrm{n}(\%)$ & $\mathrm{n}(\%)$ & \\
\hline Yes, always & $266(74)$ & $242(64)$ & $24830(88)$ & $\chi^{2}=288.50 * * *$ \\
\hline Yes, most of the time & $62(17)$ & $94(25)$ & $2439(9)$ & \\
\hline No, usually not & $23(6)$ & $31(8)$ & $720(3)$ & \\
\hline No, never & $6(2)$ & $10(3)$ & $111(0.4)$ & \\
\hline
\end{tabular}

orientation separately for gays/lesbians, bisexuals and heterosexual individuals. Bisexuals were younger and had lower income than both gays/lesbians and heterosexuals, and gays/lesbians were younger than heterosexuals. Heterosexuals were more likely to live with a partner and be born in Sweden. Gays/lesbians and bisexuals were more likely to report experiences of victimisation and threat of assaults than heterosexuals. Heterosexuals reported greater access to social support than the other groups.

\section{Prevalence of mental health treatment}

During the 12 months follow-up period, $5.8 \%$ of gay/lesbian individuals, $13.3 \%$ of bisexuals and $3.2 \%$ of heterosexuals had at least one psychiatric healthcare visit. Among those with any psychiatric healthcare visit, the mean number of visits was 5.05 for gays/lesbians with an SD of 4.52; the mean number of visits for bisexuals was $4.49(\mathrm{SD}=5.83)$ and $3.53(\mathrm{SD}=4.45)$ for heterosexuals. The difference in the mean number of visits between groups was not significant $(F=2.49, p=0.08)$. During the follow-up, $15.5 \%$ of gays/lesbians, $17.9 \%$ of bisexuals and $9.1 \%$ of heterosexuals used antidepressive medication. In adjusted analyses, gay/lesbian individuals were more likely to receive healthcare treatment for mental diagnosis and use antidepressant medication than heterosexuals (table 2). Separate analyses for specific mental health diagnose groups showed that gays/lesbians had an elevated risk of being treated for anxiety disorders as compared with heterosexuals. Bisexual individuals were more likely to receive treatment for mental diagnoses and to use antidepressive medication as compared with heterosexuals. Separate analyses for specific mental health diagnose groups showed that bisexuals had an elevated risk of being treated for mood disorders, anxiety disorders and substance-use disorders as compared with heterosexuals.

\section{Mediators of the effect of sexual orientation on mental health outcomes}

A simple mediation analysis of the mediation effect of victimisation or threat of assaults on the link between sexual orientation and mental health treatment showed a significant indirect effect $(\beta=0.03)$ and the bias-corrected bootstrap 95\% CI was above zero (0.02 to 0.06$)$. This effect was, however, not moderated by social support. As a next step, serial multiple mediation analyses were conducted (figure 1). The analyses showed significant indirect mediating effects of the link between sexual orientation and mental health treatment for both victimisation/threats and social support. In addition, the path from sexual orientation to victimisation/threats to social support showed a small but significant effect on mental health treatment. However, the direct effect of sexual orientation on mental health treatment was still significant after controlling for the indirect effects, suggesting that other unmeasured factors explain a substantial proportion of the sexual orientation-based disparities in mental health.

\section{Sociodemographic factors as moderators}

A number of sociodemographic factors were tested as moderators of the association between sexual orientation and mental health outcomes. Significant moderating effects of the association between sexual orientation and mental health treatment were found for age and gender, but not for country of birth, education, living with a partner and income. In table 2, stratified analyses for age and gender are presented for those outcomes that showed a significant interaction effect. Among gays/lesbians, sexual orientation disparities in healthcare visits for any mental diagnosis were only significant among women and younger individuals. However, large disparities based on sexual orientation were found among gay men for mood disorders and use of antidepressive medication. Disparities in anxiety disorders were only significant among 
Table 2 Adjusted exponential $\beta$-coefficient and ORs for sexual orientation-related disparities in frequency of healthcare visits for mental disorders and use of antidepressive medication in the Stockholm Public Health Cohort 2011

\begin{tabular}{|c|c|c|c|c|c|}
\hline & $\begin{array}{l}\text { Healthcare visits for } \\
\text { any mental disorder } \\
\text { Adj. Exp. } \beta(95 \% \mathrm{Cl})\end{array}$ & $\begin{array}{l}\text { Healthcare visits for } \\
\text { any mood disorder } \\
\text { Adj. Exp. } \beta(95 \% \mathrm{Cl})\end{array}$ & $\begin{array}{l}\text { Healthcare visits for } \\
\text { any anxiety disorder } \\
\text { Adj. Exp. } \beta(95 \% \mathrm{Cl})\end{array}$ & $\begin{array}{l}\text { Healthcare visits for } \\
\text { substance-related disorder } \\
\text { Adj. Exp. } \beta(95 \% \mathrm{CI})\end{array}$ & $\begin{array}{l}\text { Use of antidepressive } \\
\text { medication } \\
\text { AOR }(95 \% \mathrm{CI})\end{array}$ \\
\hline Heterosexual (reference) & 1 & 1 & 1 & 1 & 1 \\
\hline Gay/lesbian & $2.33^{* * *}(1.88$ to 2.90$)$ & $1.28(0.72$ to 2.30$)$ & $3.80 * * *(2.54$ to 5.69$)$ & 1.24 (0.69 to 2.22$)$ & $2.13^{* * *}(1.62$ to 2.79$)$ \\
\hline Male & $1.22(0.85$ to 1.75$)$ & $3.01^{* * *}(1.56$ to 5.81$)$ & & & $2.96^{* * *}(2.10$ to 4.16$)$ \\
\hline Female & $3.65^{* * *}(2.76$ to 4.82$)$ & $0.32(0.08$ to 1.29$)$ & & & 1.36 (0.87 to 2.13$)$ \\
\hline 16-34 years & $4.65^{* * *}(3.49$ to 6.18$)$ & & $8.07^{* * *}(5.04$ to 12.93$)$ & & $3.06^{* * *}(1.92$ to 4.89$)$ \\
\hline 35 years or older & $0.99(0.67$ to 1.46$)$ & & $0.76(0.24$ to 2.38$)$ & & $1.69 * *(1.21$ to 2.37$)$ \\
\hline Bisexual & $3.60^{* * *}(3.03$ to 4.27$)$ & $1.58 *(1.00$ to 2.48$)$ & $3.23^{* * *}(2.22$ to 4.72$)$ & $1.91 *(1.12$ to 3.25$)$ & $2.06^{* * *}(1.59$ to 2.68$)$ \\
\hline Male & $1.77^{* *}(1.16$ to 2.69$)$ & & & & 1.08 (0.54 to 2.14$)$ \\
\hline Female & $4.78^{* * *}(3.94$ to 5.80$)$ & & & & $2.34^{* * *}(1.75$ to 3.13$)$ \\
\hline $16-34$ years & $4.36^{* * *}$ (3.53 to 5.39$)$ & & & & \\
\hline 35 years or older & $2.46^{* * *}(1.78$ to 3.40$)$ & & & & \\
\hline
\end{tabular}

Figure 1 Multiple indirect effects of victimisation or threat of violence and social support on the relationship between sexual orientation and mental health treatment.

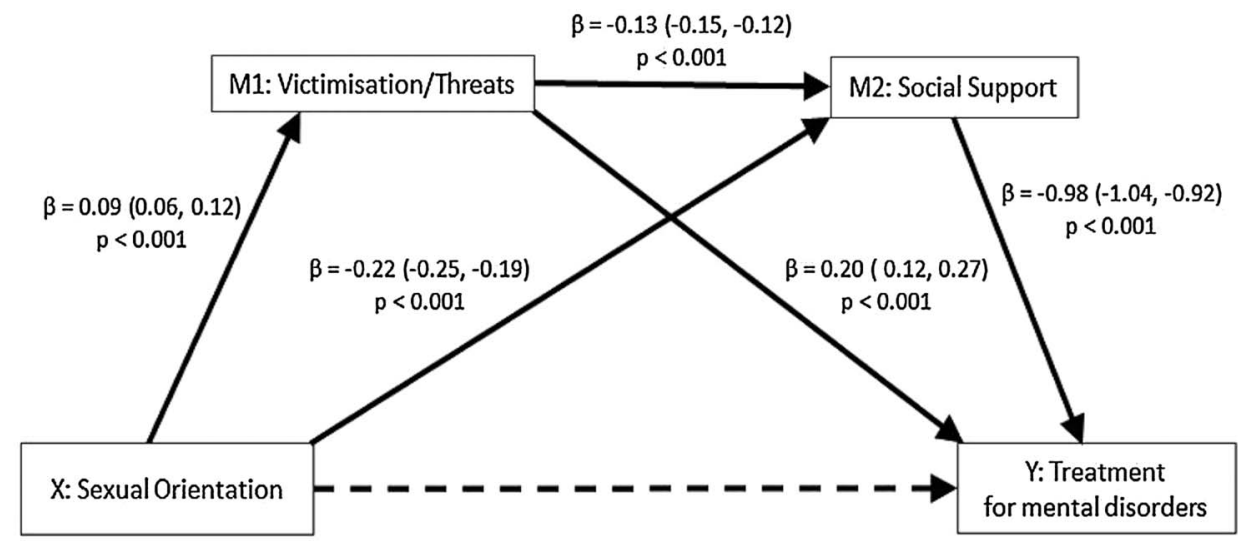

Indirect effects

$X \rightarrow M 1 \rightarrow Y: \beta=0.02 \quad(0.01,0.03)$

$X \rightarrow M 2 \rightarrow Y: \beta=0.22(0.17,0.27)$

$X \rightarrow M 1 \rightarrow M 2 \rightarrow Y: \beta=0.01(0.01,0.02)$

Direct effects

$X \rightarrow Y: \beta=0.48(0.28,0.69)$

$X \rightarrow Y$ controlling for indirect effect of $M 1$ and $M 2: \beta=0.25(0.19,0.31)$

Note: For the estimates, $95 \%$ confidence intervals are presented in the parentheses. younger gays/lesbians as compared with heterosexuals. Disparities in use of antidepressive medication was larger among younger than older gays/lesbians as compared with heterosexuals. Among bisexuals, sexual orientation disparities in healthcare visits for any mental diagnosis were larger among women and younger individuals. Disparities in use of antidepressive medication were only significant among younger bisexuals.

To give a more nuanced understanding of the intersecting influence of sexual orientation, gender and age, additional analyses were conducted using categorisation of participants based on all three of these factors (table 3). The largest mental health treatment disparities based on sexual orientation were found among bisexual women, gay men and younger lesbian women. Compared with young heterosexual men, only young gay men and young bisexual women reported more frequent exposure to victimisation or threat of assaults in the past 12 months. Lack of social support was more than five times as common among young lesbian women as compared with young heterosexual men. Young gay men, young bisexual women and bisexual men were between two and three times as likely to report lack of social support as compared with young heterosexual men.

In addition to testing the moderating effect of sociodemographic factors on the direct relation between sexual orientation and mental health treatment, moderated mediation analyses were performed to establish if the indirect mediating effects of victimisation/threats and social support on mental health treatment varied by age, gender, education, income, partnership status and country of birth. There were no significant moderating effects for any of the sociodemographic factors on the mediating effect of victimisation/threats on mental health treatment. Age, gender, level of education and income did not show a significant moderating effect of the mediating effect of social 
Table 3 ORs for sexual orientation-related disparities in treatment for mental disorders, victimisation or threat of assaults, and lack of social support in the Stockholm Public Health Cohort

\begin{tabular}{|c|c|c|c|c|c|c|}
\hline & \multicolumn{2}{|c|}{ Any treatment for mental disorders } & \multicolumn{2}{|c|}{$\begin{array}{l}\text { Victimisation or threat of assaults, } \\
\text { past } 12 \text { months }\end{array}$} & \multicolumn{2}{|c|}{ Lack of social support } \\
\hline & $\%$ (SE) & AOR $(95 \% \mathrm{CI})$ & $\%$ (SE) & AOR $(95 \% \mathrm{Cl})$ & $\%(\mathrm{SE})$ & AOR $(95 \% \mathrm{Cl})$ \\
\hline Heterosexual young men & $6.0(0.5)$ & 1 & $11.5(0.6)$ & 1 & $4.5(0.4)$ & 1 \\
\hline Gay young men & $16.5(5.0)$ & $2.30^{* *}(1.25$ to 4.25$)$ & $17.0(5.3)$ & $2.22^{* *}(1.24$ to 3.97$)$ & $12.8(4.6)$ & $3.06^{* *}(1.53$ to 6.10$)$ \\
\hline Bisexual young men & $15.9(6.6)$ & $1.82(0.88$ to 3.75$)$ & $9.5(5.3)$ & 0.80 (0.32 to 2.02$)$ & $13.2(5.5)$ & $2.81^{*}(1.25$ to 6.31$)$ \\
\hline Heterosexual mid-adult/older men & $8.1(0.3)$ & $1.30^{* * *}(1.15$ to 1.46$)$ & $3.5(0.2)$ & $0.39^{* * *}(0.33$ to 0.45$)$ & $2.7(0.2)$ & $0.81^{*}(0.67$ to 0.97$)$ \\
\hline Gay mid-adult/older men & $18.2(3.2)$ & $2.71^{* * *}(1.83$ to 4.01$)$ & $6.5(2.1)$ & $0.69(0.38$ to 1.25$)$ & $4.7(1.6)$ & 1.07 (0.52 to 2.22$)$ \\
\hline Bisexual mid-adult/older men & $12.2(3.8)$ & $1.63(0.80$ to 3.29$)$ & $2.6(1.5)$ & $0.40(0.12$ to 1.26$)$ & $8.4(3.3)$ & 2.01 (0.86 to 4.73 ) \\
\hline Heterosexual young women & $9.3(0.5)$ & $1.10(0.95$ to 1.26$)$ & $8.2(0.5)$ & $0.78^{* * *}(0.67$ to 0.90$)$ & $5.0(0.4)$ & 1.09 (0.90 to 1.32$)$ \\
\hline Lesbian young women & $20.4(5.9)$ & $2.71^{* *}(1.46$ to 5.03$)$ & $12.2(4.4)$ & 1.07 (0.48 to 2.36$)$ & $21.3(6.1)$ & $5.37^{\star * *}(2.85$ to 10.12$)$ \\
\hline Bisexual young women & $28.3(3.7)$ & $3.46^{* * *}(2.44$ to 4.92$)$ & $20.3(3.3)$ & $2.23^{* * *}(1.53$ to 3.25$)$ & $14.1(2.8)$ & $2.74^{* * *}(1.70$ to 4.42$)$ \\
\hline Heterosexual mid-adult/older women & $15.2(0.3)$ & $2.17^{* * *}(1.95$ to 2.42$)$ & $3.7(0.2)$ & $0.36^{* * *}(0.32$ to 0.41$)$ & $2.9(0.2)$ & $0.72^{* * *}(0.61$ to 0.85$)$ \\
\hline Lesbian mid-adult/older women & $12.2(3.4)$ & 1.82 (0.98 to 3.38$)$ & $5.6(2.5)$ & 0.57 (0.23 to 1.42$)$ & $3.1(1.8)$ & $0.79(0.25$ to 2.54$)$ \\
\hline Bisexual mid-adult/older women & $24.4(4.4)$ & $4.41^{* * *}(2.83$ to 6.88$)$ & $8.8(3.0)$ & 0.79 (0.38 to 1.63$)$ & $7.0(2.5)$ & $1.38(0.60$ to 3.20$)$ \\
\hline
\end{tabular}

All models are adjusted for education, income, relationship status and country of birth.

All models take into account sample weights and stratification.

AOR, adjusted ORs. * $\mathrm{p}<0.05 ;{ }^{* *} \mathrm{p}<0.01 ;{ }^{* * *} \mathrm{p}<0.001$.

support on mental health treatment. However, the mediating effect of social support on mental health treatment was larger among individuals born in Sweden $(\beta=0.24 ; 95 \%$ CI 0.19 to $0.30)$ and those living with a partner $(\beta=0.26$; 95\% CI 0.20 to $0.32)$, and lower among those born outside of Sweden $(\beta=0.18$; $95 \%$ CI 0.13 to 0.24 ) and those not living with a partner $(\beta=0.22 ; 95 \%$ CI 0.17 to 0.27$)$.

\section{DISCUSSION}

This study used prospective data from a population-based representative sample of adults with linkage to the comprehensive and high-quality health records available in Sweden to assess sexual orientation differences in mental health treatment. Our analyses suggest a substantially elevated risk of poor mental health among gay, lesbian and bisexual individuals as compared with heterosexuals. Sexual orientation disparities were present for treatment of mood disorders, anxiety disorders and substance-related disorders, as well as for treatment with antidepressant medication. The level of disparity varied substantially between individuals with varying sociodemographic characteristics, highlighting the importance of considering multiple social identities when analysing the health status of sexual minorities. The largest mental health treatment disparities based on sexual orientation were found among bisexual women, gay men and younger lesbian women. Our results gave additional support for the impact of minority stressors, such as exposure to victimisation or threat of assaults and lack of social support, in explaining these disparities. Young gay men and young bisexual women reported the largest degree of exposure to minority stressors. More than one in five young lesbian women reported lack of social support.

Our results add to the growing number of research studies showing evidence of elevated rates of poor mental health among sexual minorities. ${ }^{3} 53435$ Our results are also consistent with previous studies giving support for the minority stress theory as it demonstrates the influence of victimisation and threat of violence on mental health outcomes. ${ }^{8-10}$ However, a much stronger support was found regarding the influence of social support on mental health. Interestingly, our analyses showed a direct effect of social support on mental health outcomes but no protective or buffering effect of social support on the effect of victimisation and threat of violence on mental health outcomes as has been suggested by the minority stress theory. ${ }^{1}$ Similar findings have been reported in earlier studies, showing that social support, and especially family support, is more strongly associated with poor mental health among sexual minorities than exposure to discrimination and violence. ${ }^{36} 37$ These results suggest a need for potential reformulation of the minority stress theory. Further, our results showed a small but significant indirect effect from sexual orientation to victimisation/threats to social support on mental health. This could indicate that exposure to minority stress has a negative influence on sexual minority individuals' capacity to develop and sustain supportive social connections, which then has a detrimental effect on mental health outcomes. Further research is needed to outline the causal pathways through which the constructs described in the minority stress theory are linked and for which type of minority stressors social support has an ameliorating effect.

The stratified findings in our study are consistent with earlier research showing poorer mental health among younger, as compared with older, LGB individuals. ${ }^{13} 38$ The lack of a moderating effect of country of birth does not support an additive negative effect of multiple minority identities on mental health, and is in line with some recent studies in the USA examining the intersecting effect of race and sexual orientation on health. ${ }^{27}$

This study has several strengths, including the large representative population-based data set with information on sexual orientation and prospectively collected information on mental health status. The quality, coverage and validity of these registries has been found to be high with low degree of misclassification. ${ }^{39}$ Many studies of sexual orientation health disparities rely on non-random samples which limits the generalisability of the findings. The sample size also enabled us to test the moderating effects of several different sociodemographic factors.

Several limitations of this study should be considered. Assessment of sexual orientation was made with a single-item question of sexual orientation identity and might not be generalisable across different operationalisations of sexual orientation. We 
only had access to hospital-based mental healthcare usage; thus, some individuals who might have been solely treated within the primary healthcare system were not included in our current analyses. However, the inclusion of use of antidepressant medication compensates for this limitation to some degree. The Swedish Prescribed Drug Register covers all prescribed medication use in the population with a very high degree of coverage, and thus all individuals in our cohort with prescribed drug treatment for depression should have been identified. ${ }^{40}$ Further, our data on minority stress exposure were limited to exposure to past year victimisation/threats and social support, and we had no access to sexual orientation-specific stress exposures, for example, concealment of sexual orientation, internalised stigma and fear of rejection. Thus, future studies need to further investigate the full spectrum of mechanisms behind sexual orientation-based disparities in mental health.

\section{What is already known on this subject}

Despite significant changes in legislation and attitudes towards homosexuality during the past decades, studies have shown that gay, lesbian and bisexual individuals report substantially higher rates of adverse mental health outcomes than heterosexuals. Sexual orientation health disparities have largely been explained through minority stress theory which describes the excess stress that sexual minority individuals experience compared with heterosexuals by virtue of their stigmatised sexual orientation. The research describing and supporting these mechanisms is increasing but many studies use cross-sectional self-report measures of health outcomes and its predictors.

\section{What this study adds}

- This study shows a substantially elevated risk of mental healthcare usage among gay, lesbian and bisexual individuals as compared with heterosexuals using longitudinal non-self-report data.

- The results demonstrate the importance of considering the intersecting influence of multiple sociodemographic identities when analysing disparities based on sexual orientation. The results show that sexual orientation disparities in mental health treatment were largest among bisexual women, gay men and younger lesbian women.

- Our results give additional support to the factors outlined in the minority stress theory, such as exposure to victimisation or threats and lack of social support, in explaining the mechanisms behind these disparities.

- The elevated prevalence of mental disorders among sexual minority individuals calls for increased research to better understand the underlying mechanisms and for the urgent need to develop targeted interventions to prevent and effectively address poor mental health among sexual minorities.

Funding The study was financed by the Swedish Research Council for Health, Working Life, and Welfare (grant number 2014-0173).

Competing interests None declared.
Ethics approval Regional Ethics Committee in Stockholm at the Karolinska Institute.

Provenance and peer review Not commissioned; externally peer reviewed.

Open Access This is an Open Access article distributed in accordance with the Creative Commons Attribution Non Commercial (CC BY-NC 4.0) license, which permits others to distribute, remix, adapt, build upon this work non-commercially, and license their derivative works on different terms, provided the original work is properly cited and the use is non-commercial. See: http://creativecommons.org/ licenses/by-nc/4.0/

\section{REFERENCES}

1 Meyer I. Prejudice, social stress, and mental health in lesbian, gay, and bisexual populations: conceptual issues and research evidence. Psychol Bull 2003; 129:674-97.

2 Ploderl M, Tremblay P. Mental health of sexual minorities. A systematic review. Int Rev Psychiatry 2015;27:367-85.

3 Cochran SD, Mays VM, Sullivan JG. Prevalence of mental disorders, psychological distress, and mental health services use among lesbian, gay, and bisexual adults in the United States. J Consult Clin Psychol 2003;71:53-61.

4 Wichstrom L, Hegna K. Sexual orientation and suicide attempt: a longitudinal study of the general Norwegian adolescent population. J Abnorm Psychol 2003;112:144-51.

5 King M, McKeown E, Warner J, et al. Mental health and quality of life of gay men and lesbians in England and Wales: controlled, cross-sectional study. Br J Psychiatry 2003; 183:552-8

6 King M, Semlyen J, Tai SS, et al. A systematic review of mental disorder, suicide, and deliberate self harm in lesbian, gay and bisexual people. BMC Psychiatry 2008;8:70.

7 Hatzenbuehler ML. How does sexual minority stigma "get under the skin"? A psychological mediation framework. Psychol Bull 2009;135:707-30.

8 Balsam KF, Rothblum ED, Beauchaine TP. Victimization over the life span: a comparison of lesbian, gay, bisexual, and heterosexual siblings. J Consult Clin Psychol 2005;73:477-87.

9 Russell ST, Franz BT, Driscoll AK. Same-sex romantic attraction and experiences of violence in adolescence. Am J Public Health 2001;91:903-6.

10 Tjaden $\mathrm{P}$, Thoennes N, Allison CJ. Comparing violence over the life span in samples of same-sex and opposite-sex cohabitants. Violence Vict 1999; 14:413-25.

11 Badgett MVL, Lau H, Sears B, et al. Bias in the workplace: consistent evidence of sexual orientation and gender identity discrimination. CA, USA: Williams Institute, UCLA School of Law, 2007

12 Bildt C. Fackmedlemmars uppfattningar om diskriminering på grund av sexuell läggning på arbetsplatsen. Stockholm, Sweden: Arbetslivsinstitutet, 2004.

13 Hatzenbuehler ML. The social environment and suicide attempts in lesbian, gay, and bisexual youth. Pediatrics 2011;127:896-903

14 Hatzenbuehler ML, Keyes KM, McLaughlin KA. The protective effects of social/ contextual factors on psychiatric morbidity in LGB populations. Int J Epidemiol 2011;40:1071-80.

15 Hatzenbuehler ML, McLaughlin KA, Keyes KM, et al. The impact of institutional discrimination on psychiatric disorders in lesbian, gay, and bisexual populations: a prospective study. Am J Public Health 2010;100:452-9.

16 Mustanski B, Liu RT. A longitudinal study of predictors of suicide attempts among lesbian, gay, bisexual, and transgender youth. Arch Sex Behav 2013;42:437-48.

17 Mustanski B, Newcomb M, Garofalo R. Mental health of lesbian, gay, and bisexual youth: a developmental resiliency perspective. J Gay Lesbian Soc Serv 2011;23:204-25

18 McConnell EA, Birkett MA, Mustanski B. Typologies of social support and associations with mental health outcomes among LGBT youth. LGBT Health 2015;2:55-61.

19 Sattler FA, Wagner U, Christiansen H. Effects of minority stress, group-level coping, and social support on mental health of German gay men. PLOS ONE 2016;11: e0150562.

20 Hatzenbuehler ML, Nolen-Hoeksema S, Dovidio J. How does stigma "get under the skin"?: the mediating role of emotion regulation. Psychol Sci 2009;20:1282-9.

21 Button DM, O'Connell DJ, Gealt R. Sexual minority youth victimization and social support: the intersection of sexuality, gender, race, and victimization. $J$ Homosex 2012;59:18-43.

22 Williams T, Connolly J, Pepler D, et al. Peer victimization, social support, and psychosocial adjustment of sexual minority adolescents. I Youth Adolesc 2005;34:471-82

23 US Institute of Medicine. The health of lesbian, gay, bisexual, and transgender people: building a foundation for better understanding. Washington DC, USA: The National Academies Press, 2011. 
24 Cole ER. Intersectionality and research in psychology. Am Psychol 2009;64:170-80.

25 Sandfort T, de Graaf R, ten Have M, et al. Same-sex sexuality and psychiatric disorders in the second Netherlands Mental Health Survey and Incidence Study (NEMESIS-2). LGBT Health 2014;1:292-301.

26 Sandfort TG, Bakker F, Schellevis FG, et al. Sexual orientation and mental and physical health status: findings from a Dutch population survey. Am J Public Health 2006;96:1119-25.

27 Hsieh N, Ruther M. Sexual minority health and health risk factors: intersection effects of gender, race, and sexual identity. Am J Prev Med 2016;50:746-55.

28 Bostwick WB, Boyd CJ, Hughes TL, et al. Dimensions of sexual orientation and the prevalence of mood and anxiety disorders in the United States. Am J Public Health 2010;100:468-75.

29 Bränström R, Hatzenbuehler ML, Pachankis JE. Sexual orientation disparities in physical health: age effects in a population-based study. Soc Psychiatry Psychiatr Epidemiol 2016;51:289-301.

30 Barnes DM, Hatzenbuehler ML, Hamilton AD, et al. Sexual orientation disparities in mental health: the moderating role of educational attainment. Soc Psychiatry Psychiatr Epidemiol 2014;49:1447-54.

31 Svensson AC, Fredlund P, Laflamme L, et al. Cohort profile: the Stockholm Public Health Cohort. Int J Epidemio/ 2013;42:1263-72.
32 WHO. International Statistical Classification of Diseases and Related Health Problems, Tenth Revision (ICD-10). Geneva: WHO, 1993.

33 Hayes AF. Mediation, moderation, and conditional process analysis-a regression-based approach. New York: Guilford, 2013.

34 Gilman SE, Cochran SD, Mays VM, et al. Risk of psychiatric disorders among individuals reporting same-sex sexual partners in the National Comorbidity Survey. Am J Public Health 2001;91:933-9.

35 Marshal MP, Friedman MS, Stall R, et al. Sexual orientation and adolescent substance use: a meta-analysis and methodological review. Addiction 2008;103:546-56.

36 Plöderl M, Sellmeier M, Fartacek $C$, et al. Explaining the suicide risk of sexual minority individuals by contrasting the minority stress model with suicide models. Arch Sex Behav 2014;43:1559-70.

37 Shilo G, Mor Z. The impact of minority stressors on the mental and physical health of lesbian, gay, and bisexual youths and young adults. Health Soc Work 2014;39:161-71.

38 Patterson CJ. Sexual orientation across the life span: introduction to the special section. Dev Psychol 2008;44:1-4.

39 Ludvigsson JF, Andersson E, Ekbom A, et al. External review and validation of the Swedish National Inpatient Register. BMC Public Health 2011;11:450.

40 Wettermark B, Hammar N, Fored CM, et al. The new Swedish Prescribed Drug Register-opportunities for pharmacoepidemiological research and experience from the first six months. Pharmacoepidemiol Drug Saf 2007;16:726-35. 